\title{
Em busca do sentimento da paisagem
}

\author{
In search of landscape feeling
}

Margareth Afeche Pimenta

\section{Resumo}

Entre aproximações e distanciamentos, o sentimento da paisagem (stimmung) resulta de um longo debate que coloca em questão a racionalidade definitiva do mundo. A conflitualidade latente entre razão e emoção leva Kant a admitir a possibilidade da apreensão suprassensível da natureza. Sulzer e Herder alinham-se com ressalvas nessa direção, reconhecendo a existência de prazer ou excitação, provocados a partir da interação exterior. Carus, a partir de então, refere-se diretamente ao sentimento da paisagem, apoiado em influências cruzadas de Goethe e Humboldt. Este artigo pretende acompanhar essa trajetória de elaboração conceitual, reconhecendo à pintura a capacidade de suscitar, em Carus, o estímulo para a apreensão sensível do mundo.

Palavras-chave: paisagem; sentimento; natureza; Humboldt; Carus.

\begin{abstract}
Between proximities and distances, the landscape feeling (stimmung) is the result of a long debate about the final rationality of the world. The latent conflict between reason and emotion leads Kant to admit the possibility of apprehending nature beyond the sensitive. Sulzer and Herder align with caveats in this direction, recognizing the existence of pleasure or excitement caused by external interaction. Carus, from there, refers directly to the landscape feeling, supported by cross-influences of Goethe and Humboldt. This article intends to follow this path of conceptual elaboration, recognizing that painting has the ability to arouse, in Carus, the stimulus for the sensitive apprehension of the world.
\end{abstract}

Keywords: landscape; feeling; nature; Humboldt; Carus. 


\section{Introdução}

A ideia de paisagem relaciona-se diretamente com a era moderna. Quando o homem passa a se reconhecer como o centro da vida na terra, vê-se espacialmente circunscrito. Constrói-se como humanidade, inserindo-se na paisagem. Até então, as cenas religiosas faziam parte da esfera do imaginário. Importava-se pouco com a representação social. Na transição do mundo medieval, transformam-se as relações e os conceitos advindos das ancoragens espaciais. 0 homem reconhece-se como livre, indivíduo social, destacado das estruturas feudais, em processo de construção de novas relações com 0 ambiente. A ruptura com o antigo regime coloca em jogo a distinção entre vida rural e urbana. 0 espaço passa a ser elemento-chave e torna-se objeto de indagações. 0 homem reconhece-se contextualizado. Observa o mundo exterior no qual se insere. Inicia-se, então, um longo processo de construção da ideia de paisagem e da relação que os homens estabeleceriam com ela.

Paisagem ter-se-ia originado de pays, noção já encontrada no século $X$, que significaria então "região habitada", podendo ser, ou não, claramente delimitada. Aparece dessa forma, na obra $A$ vida de Saint Léger, escrita em $980{ }^{1}$ No início do século XII, novos sentidos são adicionados a essa concepção original. Insere-se a ideia de divisão territorial ou região geográfi$\mathrm{ca}$, considerada tanto do ponto de vista físico como climático, que se acrescentam à definição anterior de povoamento. Acrescenta-se, também, o sentido de pertencimento, e pays passa a ser considerado o território ao qual se pertence, do qual se é originário² (CNRTL, 2015). Aparece, portanto, a relação com o meio em que se vive.

Pays ter-se-ia originado de pagus, canton, ager pagensis ou pagesius, território de um cantão, de onde, por extensão, decorrem os sentidos de região e de pátria (Littré, 1874, p. 1021). As línguas latinas derivariam a palavra paisagem do francês paysage. Existe, no entanto, uma controvérsia quanto a sua origem advir de pays ou da palavra italiana paese (Richelet, 1728, p. 10). Reconhece-se, contudo, tanto num caso como no outro, a sua formação a partir da raiz latina pagus, que designaria uma circunscrição territorial rural na época galo-romana. Significaria, então, "cantão rural" ou "território definido por seus limites", este último podendo ser decorrente do verbo pangere que corresponde a fincar um marco na terra (tradução nossa) (CNRTL, 2015). Na Idade Média, pagus adquire o significado de território de uma civitas. Posteriormente, na Gália se define como uma circunscrição inferior a civitas (ibid.), com a conotação de burgo, vila, parte de um território (Bréal e Bailly, 1885, p. 241).

0 termo paisagem é atestado pela primeira vez em francês somente no século $X V$, em 1493, quando Jean Molinet a utiliza para designar um quadro com a representação de um cenário natural (Filleron, 2005). Em 1606, aparece uma pequena definição de paisagem como "palavra comum entre os pintores" (Nicot, 1606, p. 453; tradução nossa). Até 0 início do século XVII, portanto, a paisagem está ligada ao âmbito pictural. A partir de então, desde a primeira versão (1694) dos dicionários da Academia Francesa até a última (1992), a paisagem adquire duplo sentido, por 
um lado como extensão ou pedaço de terra e, por outro, como representação pictórica (FR, 1694,1762,1798,1832-5, 1932-5, 1992; Féraud, 1788).

0 sufixo age, acrescido então a pays, que conforma paisagem (paysage), designa, quando vem depois de um verbo, uma ação; quando colocado depois de um nome de pessoa, um estado; e, depois de um nome de coisa inanimada, uma coleção (Filleron, 2005). Parece haver, atualmente, uma inclinação pela última acepção e a generalização da noção de paisagem como coletânea de objetos naturais e culturais.

Numa época em constante intervenção do homem sobre a natureza, em que as técnicas se desenvolvem rapidamente, a compreensão do mundo estaria associada à objetividade da observação racionalista. Assim, a paisagem como conjunto de objetos seria analisada com o distanciamento do investigador, em sua exterioridade. Ela apareceria, dessa forma, sob e para o olhar inquisitivo. Não haveria lugar, portanto, para um relacionamento variável entre 0 sujeito e o objeto a ser analisado. Somente no âmbito artístico haveria a permissão à contemplação evasiva.

0 conflito entre conhecimento e intuição perpassaria grande parte da história da filosofia, sobretudo alemã, como se pudesse haver, até mesmo, o risco de uma certa perversão da razão, provocada pela emoção. Uma longa trajetória de reações e argumentações promove a diluição de algumas barreiras e mesmo, em alguns momentos, um convívio entre os dois termos que pareciam historicamente antagônicos. A apreensão do real pelo conhecimento traz à luz o questionamento do próprio objeto "externo", então natureza e, com ela, a natureza transformada (Lefebvre, 1974). Sua objetividade seria questionada pela capacidade de estupefação da obra pictural, de onde decorre a elaboração do sentimento da paisagem (stimmung).

Entre aproximações e distanciamentos, o sentimento da paisagem (stimmung) resulta desse longo processo histórico que coloca em questão essa dualidade conflituosa na apreensão do real. Elabora-se a partir das reflexões de Carus sobre a evocação sensível da obra pictural. Contemporâneo de Goethe e Humboldt, pôde ser mandatário de influências cruzadas, mas, contrariamente aos demais, direciona 0 foco diretamente à paisagem cuja reflexão se desenvolve a partir da obra pictural. A vida mais uma vez imitaria a arte. Dessa associação, depreende-se a capacidade de fascínio do belo, que poderia ser capaz de suscitar interações emocionais. Stimmung não pode se restringir, no entanto, a algo similar a alguma alteração de humor (Oxford Research Encyclopedias, 2015). Seu debate circula entre os diversos significados de "vocação, ressonância, tonalidade, ambiência, acordo afetivo subjetivo ou objetivo" (Richir, 2015). Resulta, no entanto, de um embate conceitual que tem por objetivo colocar em dúvida a racionalização do mundo. $A$ tessitura dessas reflexões modernas apoia-se, historicamente, sobre a relação que se estabelece entre razão e sentimento.

Este artigo pretende acompanhar essa trajetória de elaboração conceitual, colocando em destaque os debates realizados a partir do século XVII que culminariam, aqui, na elaboração do sentimento da paisagem. Numa época em que as contextualizações parecem perder ressonância, talvez se tornem ainda mais necessárias para a construção de um debate intelectual profícuo, quando se pretende 
a elaboração da complexidade (Morin, 2003). Procura-se, assim, iniciar, aqui, uma reflexão sobre a trajetória que poderia ter conduzido à elaboração do sentimento da paisagem. Tece-se, portanto, neste momento, um percurso histórico que procura demonstrar as dubiedades necessárias às formações conceituais, o que poderia nos permitir desvendar o mundo de forma mais sedutora.

\section{Construindo o sentimento da paisagem (stimmung)}

0 conceito de stimmung teria surgido no último terço do século XVIII, com várias nuances, a partir do debate de ideias que se interagiam na Alemanha. As tônicas efetuadas variavam segundo os diversos autores. 0 debate filosófico centrado na sensibilidade alemã da era romântica aporta, entretanto, grandes inovações. 0 significado estético e teórico dos sentidos, que tradicionalmente foram considerados menos relevantes na apreensão do real, é reavaliado a partir das novas perspectivas antropológicas. 0 sentir vem se acrescentar às faculdades da alma, compreendido então quase como um contato direto com o objeto do conhecimento (Martinelli, 2010, p. 1).

Uma longa história de indagações sobre as relações entre o pensar e o sentir vai ser tecida até o reconhecimento da apreensão sensível do real. Para Kant, considerado o predecessor do debate entre razão e sensibilidade, o homem, em condições de universalidade, é chamado a formar juízos, a partir do entendimento e do sentido reunidos (Kant, 1846, p. 94). Procura estabelecer leis que possam ser explicadas com a ajuda do conceito de entendimento da realidade sensível. A faculdade de julgar estabeleceria um princípio de relação da "natureza com o inacessível mundo do suprassensível" (ibid., p. 7). 0 entendimento estabelece-se a partir de leis gerais da natureza, que estão dadas a priori, sem as quais não se poderia aproximar do objeto da experiência. Existe a necessidade de certo ordenamento da natureza nas suas regras particulares, que somente são conhecidas empiricamente e que são contingentes (ibid., p. 36). A concordância da natureza, considerada na variedade de suas leis particulares, deve ser julgada como contingente em nosso espírito, mas, ao mesmo tempo, como inevitável para o nosso entendimento e, assim, como uma finalidade pela qual a natureza se justifica ao nosso olhar, quando se trata do processo de conhecimento (ibid., p. 40).

A natureza teria para Kant duas finalidades (forma finalis), formal ou real. A primeira seria julgada pelo gosto; a segunda, pela razão. A existência de um substrato suprassensível da natureza estabeleceria a possibilidade de "ser determinado pela nossa capacidade intelectual" (ibid., p. 58). Na apreciação da beleza, qualidade universal, o "julgamento do gosto é puro; não supõe o conceito de finalidade, à qual se reportariam os diversos elementos do objeto" (ibid., p. 112). Colocando em questão o julgamento do gosto, Kant enaltece as possibilidades da apreensão suprassensível da natureza, chegando mesmo a detectar uma certa perversão da razão pela paixão. Haveria, portanto, uma espécie de bloqueio da capacidade de racionalização, decorrente da sobreposição da emoção (Richir, 2015). Essa conflitualidade em nada contribui para diminuir 0 papel que desempenha o sensível no processo 
de conhecimento, enquanto método de atingir o entendimento a partir da experiência, mas também diferenciação entre o entendimento e a sensação, elemento puramente subjetivo da relação com o real. 0 sentimento do prazer é também determinado por uma razão a priori, que the atribui um valor universal, referente à relação do objeto com a faculdade de conhecer, sem que o conceito de finalidade se refira à faculdade de desejar, diferenciando-se, portanto, da finalidade prática da natureza (Kant, 1846, p. 41). 0 debate estético introduzido por Kant em 1790 constitui uma primeira definição de Stimmung, quando coloca em "acordo proporcional" os diferentes instrumentos de julgamento entre o gosto pela beleza, o entendimento e o sentido (Wellbery apud Pierlot, 2015).

A preocupação de Kant com a apreensão estética encontra eco em Sulzer, mas este privilegia a metáfora musical e a experiência emocional. Pela falta de tradução e de difusão, sua obra é pouco conhecida, sobretudo no que concerne às relações que estabelece entre prazer e conhecimento. Segundo Sulzer, as ideias seriam produzidas pela força da alma, que optaria pelas ideias claras ante as obscuras. Os homens prefeririam, então, uma representação distinta a uma confusa, porque a primeira poderia ensinar mais e, portanto, satisfazer meIhor "as necessidades da alma" (Sulzer apud Décultot, 2006, p. 94). 0 mais simples objeto, que em si é incapaz de estimular um sentimento de prazer, poderia "suscitar um sentimento agradável, quando a imaginação ou o entusiasmo impulsiona a procura do belo" (ibid., 2012, p. 96). Em sua Nouvelle Théorie des Plaisirs de 1767, a fonte do prazer residiria no objeto, que detém a perfeição, mas também na dinâmica da própria alma. A natureza da atividade da alma estaria fortemente relacionada ao objeto percebido. 0 prazer seria um estado qualitativo dos sentidos ou do intelecto, provocado pelas "qualidades gerais que os objetos devem ter para estimular naturalmente esses sentimentos" (Sulzer apud Mondzain-Baudine, 2015). 0 fator supremo do prazer estaria na unidade resultante da harmonia convergente das partes para a formação do todo.

0 belo provocaria o efeito de estimular, com intensidade particular, as faculdades da alma. Todo objeto reconhecido por belo teria "a virtude de excitar a vivacidade do espírito" (Sulzer apud Décultot, 2006, p. 98). Acima de qualquer outra experiência, aquela exercida pelo belo teria o privilégio de fazer experimentar a essência do prazer, essa "impulsão da alma" a "abraçar uma infinidade de ideias", a fazer com que se relacionem entre elas (ibid.). Seriam as qualidades de ordem e de complexidade que provocariam o prazer. A multiplicidade dos gostos e de prazeres, resultado da desigualdade de conhecimentos, não poderia originar a universalidade fundamental da beleza. 0 belo, o julgamento de gosto, se aprende. A única condição para que o belo provocasse seu efeito seria conhecê-lo. 0 caráter universal da beleza não pressupõe, entretanto, sua unicidade. A obra provoca o sentimento, mas este se educa (Mondzain-Baudine, 2015).

No entrecruzamento das posições, Herder alinha-se ao pensamento de Sulzer, atribuindo-lhe o papel de precursor nesse debate, o que é coerente com sua própria visão da relação entre os sentidos e a razão, explicitada sobretudo na obra Plastik de 1778 (Decultot, 2006, p. 103). Contemporâneo de Kant, estabelece com este uma polêmica sobre a capacidade 
de julgar, ${ }^{3}$ afirmando que é a mesma mente que percebe, imagina, pensa ou legisla. Existe, portanto, uma mesma capacidade com várias atribuições. A razão aparece na mente humana sem estar separada de outras "faculdades" (Clark, 1955, p. 400). Haveria, portanto, um único âmbito de pensar e sentir. Kant considera a sensação como uma percepção objetiva, enquanto o sentimento é sempre e somente subjetivo, sem constituir uma representação do objeto. Herder se opõe à objetivação das sensações, porque não admite a separação kantiana entre sensibilidade e intelecto (Martinelli, 2010, p. 6).

A razão não prescinde, no entanto, da experiência. Quanto mais se observa e se procura compreender o grande espetáculo das forças da natureza, menos se pode evitar de sentir [fühlen] em todos os lugares uma certa afinidade e de tudo animar com a nossa sensação [empfindung] (Herder, 2009, p. 99). ${ }^{4} 0$ ser humano que sente, "se sente em tudo e ali imprime sua imagem e sua marca" (ibid., 2013, p. 10). A excitação seria a primeira faísca em direção à sensação. 0 pensamento não poderia emergir se a sensação não se produzisse anteriormente, considerando que nada pode ser separado na natureza, mas que tudo flui através e por meio de transições imperceptíveis (Herder, 2013, p. 22).

Apesar das divergências salientadas, existem muitas aproximações ou suportes que resultam no desenvolvimento do pensamento posterior sobre o papel das sensações no processo de conhecimento. Como Kant, Herder reconhece que existe uma excitação da alma provinda do exterior e, para isso, os homens foram dotados de sentidos. A divindade teria dotado os homens de sentidos para que a alma acolhesse "o mar de estímulos e sentimentos [Gefühl] que provêm do exterior", mas, ao mesmo tempo, teceu um sistema nervoso para receber os estímulos provenientes do interior (ibid., p. 31). Esse "éter interior" não tem necessidade de luz, som ou odor, mas "pode tudo acolher e transformar em si". Todos esses elementos compõem o "jogo de cordas da divindade", que pode demonstrar que "nenhum pequeno elo possa ser sem razão" (ibid., p. 38).

Os sentidos estão, então, em estreita conexão e são unificados interiormente. A vista e o olfato se decifram mutuamente; o olfato parece ser o espírito do gosto, ou é um irmão próximo para o paladar. Sente-se aquilo que os nervos permitem (ibid., p. 37). "A partir de tudo isso, a alma tece e se confecciona um vestido, seu universo sensível" (ibid., p. 36; grifos nossos). Atribui, entretanto, um papel diferenciado ao tocar, o órgão da copresença. Somente o tocar restitui a "forma", um conceito essencial em estética, enquanto a vista só revela a "superfície" (Martinelli, 2010, p. 3).

A vista possibilitaria o sonho, o toque revelaria a verdade, em termos da passagem da fantasia à realidade, da representação à coisa (ibid.). É preciso ter em conta a ambiguidade do termo Gefühl que "designa ao mesmo tempo o tocar (sentido externo) e o sentimento, em seu duplo sentido ético e estético" (ibid., p. 1). Isso se faz presente em todo o Século das Luzes alemão, sem que as implicações de seu valor semântico sejam totalmente exploradas, mas com consequências sobre a maneira de pensar as relações entre o mundo exterior e o sentimento.

Pela experiência, reconhecer-se-ia que tudo está cheio de excitação e de vida, o que formaria em nós uma unidade, "uma alma 
humana, que todas as obras e impulsões e todos os membros mecânicos servem voluntariamente". Enquanto presença, "essa unidade convergente e animada em nós se chama imaginação", quando se lhe atribui seu próprio alcance. "No contexto das forças intelectuais, espaço e tempo, que parecem existir somente para o mundo robusto dos corpos, desaparecem" (Herder, 2013, p. 39).

Herder exerceu uma enorme influência sobre a antropologia, geografia, filosofia da história, tal qual sua obra Ideen que junta muitos assuntos - história natural, história da humanidade, literatura, filosofia - sem seguir uma classificação enciclopédica, mas segundo o duplo processo de progressão e de antologia (Pénisson, 1996, p. 63).

Herder, assim como Rousseau, acreditava que a evolução da civilização tinha alienado a humanidade da natureza - ou seja, da própria natureza inerente à humanidade e do meio ambiente. Ele advogava que as diferentes formas de arte tiravam sua energia da experiência direta e não da correção das normas impostas, recusando os modelos universais do classicismo francês (Hill, 2013, p. 1101). Atribui, como os mais importantes autores alemães da época, a primazia à experimentação e ao sensível no processo de elaboração artística.

Herder foi o pai intelectual do movimento romântico Sturm und Drang (Tempestade e Paixão) que teve em Goethe sua figura central. 0 encontro com Herder em Estrasburgo, em 1770, permitiu a Goethe descobrir seu próprio potencial como escritor original. 0 Sturm und Drang teve curta duração como movimento literário, mas foi um importante precursor do Romanticismo em seu experimentalismo formal, seu entusiasmo pela cultura popular e o primitivo, sua aceitação do poder do inconsciente, forças irracionais e, acima de tudo, sua relação com a experiência individual (ibid.). Enquanto Herder erige Sulzer no verdadeiro mentor de uma verdadeira ciência do sentir, Goethe o considera gestor de uma concepção moralizadora e insensível da arte (Décultot, 2006, p. 106). 0 debate seguia, portanto, entre convergências e dissonâncias, elaborando de forma cada vez mais complexa a relação entre ideia e sensações.

A apreensão do real pela sensação, elaborada pela razão, demonstra-se insuficiente para responder à elaboração artística. Em uma carta endereçada a Goethe, em 1794, Schiller desenvolve a ideia da interação entre intuição e abstração como via de mão dupla (Schiller e Goethe, 1923). Assinala que existe uma tarefa a mais, porque, depois de ter passado da intuição concreta à abstração, ter-se-ia que tomar o caminho inverso, "traduzir de novo as ideias abstratas em intuição" e transformar pensamentos em sentimentos, já que somente "as intuições concretas fornecem a matéria prima à produção criadora do gênio" (Herr, 1923, p. 7).

Entre sentimento, arte e razão vão se desenvolver as primeiras impressões que permitem posteriores reflexões sobre a paisagem como percepção e sensações. Elaboram-se, portanto, as primeiras ideias da apreensão da paisagem como preocupação primordial, polemizando entre as expectativas de compreensão e os sentimentos suscitados. 


\section{A paisagem como stimmung}

Do embate cooperativo e ao mesmo tempo conflituoso entre razão e sensações, a paisagem parece, pela primeira vez, ser o alvo de preocupação, mas também um ponto de referência para a harmonia entre essas duas percepções aparentemente contraditórias. Esta se revela em estreita associação com a arte, porque ambas pressupõem a cooptação sensitiva. A paisagem provoca sensações. São elas que devem ser transmitidas pela arte e pela pintura. Em sua Nove cartas sobre a pintura da paisagem (Neun Breife über Landschafsmalerei), Carus e Friedrich (1983) colocam em destaque a paisagem enquanto sentimento. Aparece, portanto, pela primeira vez, de forma clara, o estabelecimento de uma ligação sentimental com 0 ambiente. Até então, sensação e conhecimento estavam entre os questionamentos primordiais. Agora, é a paisagem que se vincula diretamente à arte e à pintura. Paisagem e beleza então se confundem, considerando as perturbações emocionais que advêm dos estímulos provocados pela contemplação. A paisagem associa-se diretamente à beleza e, portanto, à arte.

A paisagem imediatamente percebida transmite sensações, como a neve nos reporta à calma e à tranquilidade (Carus e Friedrich, 1983, p. 57). 0 espírito se abandona, então, à paz e aos pensamentos. Existe, dessa forma, uma relação positiva entre razão e emoção. Os pensamentos se realizam nesse abandono em um clima de paz, que advém do contato que se estabelece com a paisagem. A paisagem passa a ser a estimuladora de um processo complexo de elaboração artística e intelectual. A paisagem retratada transmite, assim, esse sentimento "reconfortante de tranquilidade e de clareza interior" (ibid., p. 65). Sensação e pensamento caminham, portanto, de forma indissociável.

Para atingir a beleza e a grandeza, o homem precisa se sentir "em harmonia consigo mesmo". O homem íntegro apreende a beleza em sua interioridade, desde que seja abordada "com toda a sua alma" (ibid., p. 58). A integridade humana somente pode ser atingida na aproximação com a beleza que não é nada além "daquilo que provoca a sensação da essência divina na natureza, quer dizer no mundo dos fenômenos sensíveis" (ibid., p. 77).

Nada pode ser belo sem a interpretação "perfeita da razão e da natureza", como uma revelação divina que se expressa através dessas formas. A ideia aparece ao mesmo tempo que a natureza, que é penetrada pela razão. 0 eu entra, então, "em relação com essa infinidade aparente, e a sensação, o sentimento [fundado sobre a orientação para o infinito...], será determinado como sentimento de beleza". Esta é decorrente desse triplo acordo entre Deus, a natureza e o homem (ibid.). A paisagem desperta, portanto, esse sentido do belo, cuja contemplação procede da consciência.

As impressões retidas na observação de uma paisagem permitem julgar os efeitos que podem ser produzidos em um quadro. Seriam relações similares. Somente o que está "em ligação estreita" pode emocionar pelo olhar, mas também pelo "perfume das flores" (ibid., p. 65). A percepção não se restringe, portanto, à aparência. Além do aspecto visual, a paisagem propaga um complexo de perturbações estimuladas pelo contato sensorial. $A$ arte da paisagem significa, então, uma "representação de uma certa tonalidade da vida afetiva (sentido) pela reprodução de uma tonalidade da vida natural (verdade)" (ibid., 
p. 70). De novo, a natureza se manifesta estimulando emoções, por uma relação afetuosa estabelecida com o observador.

Carus aceita o romantismo de Schelling, Schlegel e Friedrich, visando, no entanto, uma restituição exata do real, pouco compatível com a abordagem subjetiva e mística do universo. Seria Goethe quem teria alcançado o encontro harmonioso entre arte e ciência, ou seja, a "visão poética da natureza com as exigências do saber cientifico" (Décultot, 2015). Reportando-se aos estudos sobre as nuvens (longos estudos sobre as leis da atmosfera) no Terceiro Caderno da Naturwissenschaft (Ciências Naturais) e aos seus belos poemas Howard's Ehrengedächtnis (Memória de Honra de Howard) de Gothe, Carus destaca que a pureza da vida existe somente em duas situações: 1) no ingênuo estado original, onde o divino indica o que é verdadeiro e justo, sem necessidade de reflexão; e 2) num estágio mais adiantado da vida quando se descobre "claramente quais são as relações com Deus e com o mundo". Nesse momento, essa "pureza interior, inconsciente dela mesma, recebe na vida seu carimbo de clareza e consciência" (Carus e Friedrich, 1983, p. 102). Tal dualidade na perfeição interior pode ser imaginada igualmente na arte.

Os estudos sobre a formação das nuvens, tal como são oferecidas pela simples intuição sensível, requisitam a inteligência que é fruto exclusivo da pesquisa científica. As passagens das nuvens "não são desprovidas de lei". A visão romântica da paisagem pictural conduz, assim, a uma abordagem científica da natureza, "o que não nega, entretanto, sua matriz subjetiva e poética" (Décultot, 2015).
A arte aparece, então, como apogeu da ciência. Torna-se mítica "no verdadeiro sentido do termo, ou órfica, como Goethe a qualificou igualmente" (Carus e Friedrich, 1983, p. 103). A poesia, que surge anteriormente à pintura da paisagem e que a ultrapassa em termos de espiritualidade, daria os exemplos "mais nobres" às tarefas dos tempos modernos. Ninguém seria, assim, melhor que Goethe para ser seguido, já que "através de suas descrições [...] se sente [...] que o poeta tem da natureza desses fenômenos um conhecimento íntimo e universa" (ibid., p. 108). Universalidade esta que poderia ser compreendida em relação tanto à abrangência quanto à generalização a outros campos do conhecimento.

Em sua visão, Goethe teria aberto a via à regeneração da paisagem pictórica, o que se fundamentava em dois processos de conhecimento: 1) a decomposição científica dos fenômenos naturais em conformidade, principalmente, com as leis da geologia e da meteorologia; e 2) recomposição da unidade estética pelo olhar poético do artista (Décultot, 2015). Assim, a paisagem deveria representar a "vida da terra", em sua "diversidade de figuras e fenômenos variados" (Carus e Friedrich, 1983, p. 63). A realidade seria, portanto, determinada pelos mecanismos físicos que regem 0 globo terrestre, sendo insuflada de vida pelas formas artísticas. A paisagem torna-se, assim, geognose, conceito que se desenvolve a partir do contato com Humboldt, complementando os aportes efetuados por Goethe.

A natureza considerada racionalmente, ou seja, submetida ao pensamento, seria "a unidade na diversidade dos fenômenos, a harmonia entre as coisas criadas", que diferem 
pelas formas, pelas suas constituições e pelas forças que as animam (Humboldt, 1855a, p. 4). A natureza não perderia "seu charme e o prestígio de seu poder mágico" na medida em que se "penetre em seus segredos" (ibid., p. 20). Descobri-la, portanto, seria a revelação de sua magia, a "influência do mundo exterior" se exercendo "sobre a imaginação e o sentimento" (ibid., p. 50).

Humboldt desvenda um sentimento de natureza, "desenha com palavras, para os olhos de nossa alma", inspirando, para Carus, o "ideal da paisagem artística moderna" (Carus e Friedrich, 1983, p.108). Seria necessário, então, precisar o termo paisagem como " a representação da vida da terra, a arte da representação da vida da terra (Erdlebenbild, Erdlebenbildkunst)" , o que evocaria mais precisamente seu pensamento (ibid., p. 109).

Todo o objeto na terra, por mais simples, seria um "digno e belo objeto de arte", desde que fosse apreendido com a "alma", desvelando, exatamente, "todo o seu sentido próprio e a ideia divina que se esconde nele mesmo" (ibid., p. 109). A imagem da vida na terra deveria acolher, não somente a paisagem natural, mas também a vida humana, já que o homem é o seu "mais belo produto" (ibid., p. 110).

Os artistas de "corações puros e leais" deveriam reconhecer o caráter "sagrado" de tudo o que devem representar (ibid., p. 122). Seria necessário, então, a formação do sentido do artista pela "bela forma", assim como a formação do gosto no povo. Aproxima-se de seus antecessores, sobretudo de Sulzer, quanto à necessidade de um processo de elaboração $\mathrm{e}$ desenvolvimento do gosto. 0 belo estaria em "tudo aquilo que exprime puramente uma essência divina nas coisas naturais", ou seja, dito de outra forma, "tudo aquilo onde a natureza se revela conforme sua essência mais íntima" (ibid. p. 123). 0 "todo penetrado pelo sopro de vida" (Humboldt, 1855a, p. 4). Por isso, os desenhos dos geognosistas são animados de vida interior. 0 mesmo aconteceria com os trabalhos dos intelectuais, já que a apreciação da beleza depende da formação e do aprendizado do gosto.

0 estudo dos objetos naturais deveria, também, ensejar um aspecto exterior e um aspecto interior; o primeiro daria uma ideia intuitiva do todo, enquanto o segundo apresentaria as suas partes. Somente os dois aspectos reunidos poderiam dar a "ideia completa da essência geral do objeto natural". Da mesma forma, a compreensão do "verdadeiro caráter" de um animal não supõe somente "a reprodução inerte de seus contornos, mas a apreensão viva do olho do artista". Também parece impossível detectar a verdadeira particularidade de uma montanha, a não ser pela figuração artística, ou seja, "uma paisagem verdadeiramente geognósica" (Carus e Friedrich, 1983, p. 136).

Apreende-se o mundo sensível em seu conjunto, similar ao prazer da contemplação que se tem, avistando-se a paisagem a partir de uma montanha. Carus ressalta essa exultação, quando se intensifica a impressão de conjunto dessa apreciação. Todo estudo verdadeiro da natureza conduziria o homem ao limite dos "mistérios superiores" que lhe preencheriam de "um horror o mais sagrado" (Carus e Friedrich, 1983, p. 59). Habituando-se a ver nas características das montanhas e das nuvens os estados diversos da totalidade orgânica da terra e de sua atmosfera, Carus afirma ter desenvolvido um profundo "respeito pela particularidade da natureza", o que lhe conduziria 
para uma pesquisa rigorosa da verdade (ibid., p. 135). Considera, portanto, como Humboldt, que as atividades artísticas e a ciências interagem de forma benéfica.

Os amplos painéis geográficos descritos em Viagem às regiões equinociais do novo continente (1845-1862), de Humboldt, pretendem o maravilhamento com as particularidades naturais, assimilando o olhar inquisidor do cientista ao campo artístico (Humboldt e Bonpland, 1814). Torna-se clara sua intencionalidade em Tableau de la Nature, quando se propõe a "contemplar a natureza do alto, colocar em evidência a ação combinada das forças físicas", oferecendo, ao "homem sensível", os prazeres sempre renovados pela "pintura fiel das regiões tropicais" (Humboldt, 1850, p. 2; grifos nossos).

Para Humboldt, um estudo da natureza não seria completo quando não fosse considerado o reflexo do mundo exterior no pensamento e na imaginação das impressões poéticas, ou seja, a revelação de um mundo interior (Humboldt, 1855b). A pintura da paisagem seria uma descrição animada do mundo, que propagaria o estudo da natureza. Ela mostraria o mundo exterior, mas poderia relacionar o mundo visível ao mundo invisível, dependendo de sua qualidade.

Para compreender a natureza em sua totalidade, não se poderia reter no fenômeno exterior, mas seria necessário "fazer entrever algumas dessas analogias misteriosas e harmonias morais" que o vinculam ao mundo exterior, mostrando como a natureza pode envolver num "véu simbólico que deixava entrever imagens graciosas", como faz eclodir o "nobre germe das artes" (Humboldt, 1855b, p. 3).
Trazida ao primeiro plano por Carus, a função do gênero paisagístico seria de representar, então, uma certa tonalidade (stimmung) da vida interior, em correspondência com a vida natural, uma formulação próxima de Schlegel em Leçons sur l'art (Décultot, 2015). Schlegel segue a visão total da obra que ultrapassa a soma dos elementos que a compõem. Detectar uma verdadeira característica implica essa penetração da ideia geral que permite à literatura e ao quadro "viver organicamente". A ideia somente valeria "dentro do espírito de sua época" (Korinman, 2015). Carus, herdeiro de forte tradição conceitual e afinado com seu tempo, destaca a paisagem como objeto de reflexão das sensações no processo de conhecimento e percepção da realidade que o circunda, mas também a própria capacidade da natureza de suscitar emoções. A pintura da paisagem, repetindo o real, deveria envolver os mesmos sentimentos de uma apreensão imergente. Somente um homem alerta, que desenvolveu suas capacidades, aproximando-se do belo, seria capaz de captar a interioridade do campo externo. Um estado poético requereria, portanto, todas as potências da alma para a apreensão da realidade exterior. Ratifica, assim, "a afinidade do homem com o espírito do mundo" (Carus e Friedrich, 1983, p. 59).

\section{Paisagem e arte: identidade na busca do sublime}

Que ninguém é o igual ao outro, que seja de preferência igual ao Supremo; E de que maneira? Sendo perfeito em si mesmo. (Ibid., p. 103; grifos nossos) 
Talvez o critério da paisagem seja a busca da perfeição. Cabe, no entanto, ao observador ou ao pintor a extração do sublime. A materialidade contida no ambiente pode ser compreendida de diversas formas. É resultado de relações sociais historicamente determinadas (Santos,1982 e 1985). Apesar da justeza dessa concepção, ela não esgota o potencial das interações que se estabelecem entre o cotidiano das pessoas com o seu entorno. A paisagem pode estimular sentimentos, criar identidades, fazer sonhar.

Despertar o devaneio aparece hoje como uma qualidade simples e corriqueira, quando se estabelece uma relação com uma paisagem que se considera distintiva ou especial. A paisagem passa a ser única e inconfundível e, ao mesmo tempo, capaz de provocar alterações sensíveis. Essa assimilação cultural, que automatiza ideia e comportamentos, deve-se, no entanto, a um longo processo histórico de contestação da onipresença da razão na apreensão do mundo exterior. A conflitualidade entre razão e emoção passa a ser centro de inquietações ao menos a partir de Kant, o que traria consigo incertezas quanto à problemática da relação entre sujeito e objeto da observação. Kant se interroga se o sentimento de prazer precede, ou não, a consideração do objeto no julgamento do gosto (Pierlot, 2015). A universalidade do sentimento de prazer seria determinada por uma razão a priori, referente à relação do objeto com a faculdade de conhecer. Quando se refere ao gosto e à capacidade de julgar, Kant coloca em relação entendimento e sentimento.

A partir de então, Sulzer reconheceria a capacidade de o belo excitar o espírito, ao menos, aquele que possui vivacidade. 0 belo estimularia, com intensidade particular, as faculdades da alma. Alinhando-se com Sulzer nesse sentido, Herder contesta a distinção kantiana e identifica um único âmbito para o pensar e o sentir. Filia-se, no entanto, à linha de seu pensamento quando reconhece que os homens podem experimentar certa excitação da alma pelo contato com o mundo exterior, pois são, para isso, dotados de sentidos. As diferentes formas de arte seriam, portanto, impulsionadas pela aproximação com o real, devido ao papel primordial desempenhado pela experimentação no processo de elaboração artística.

Estariam desvendadas, até então, as correlações complexas estabelecidas entre sentimento e arte, mas seria de Humboldt a iniciativa de fazer despertar o olhar para a natureza, indo além das características formais. Reconhece, portanto, um aspecto exterior e um interior nos objetos naturais. 0 primeiro proporcionaria uma ideia intuitiva do todo, enquanto o segundo apresentaria as suas partes. Até então, retrata-se a intenção de uma análise da totalidade do objeto, mas vai mais além. 0 estudo da natureza jamais poderia ser pleno sem que fosse considerado o mundo exterior e seu reflexo no pensamento e na imaginação, ou seja, sua influência em um mundo interior (Humboldt, 1855b). A ideia da "essência geral do objeto natural" somente poderia resultar da combinação dessas duas dimensões. Tratava-se de revelar interiormente a magia contida na natureza.

Uma vez delimitada, a natureza transforma-se em paisagem. 0 olhar seletivo de um recorte efetuado pelo artista atrairia a atenção para o significado do sublime que se pode observar na natureza. 0 belo seria uma revelação divina expressa através das formas. A pintura 
da paisagem teria sido o mote de incitação da observação do belo que se interioriza, a partir da aproximação com a natureza. 0 eu entraria em contato consciente com as sensações, de onde se depreenderia o sentimento de beleza.

Carus, entremeando as visões mais científicas e as mais naturalistas de Goethe e Humboldt, desenvolve uma percepção original de paisagem, que aparece associada diretamente à alma e ao sentimento. Esse foi um primeiro passo que seria seguido, posteriormente, por diversas versões controversas e criativas, o que não é objetivo deste texto desenvolver. Cabe somente destacar a importância do debate contraditório como método de formação conceitual. As novas tecnologias fizeram obliterar a duração como elemento fundamental da compreensão da realidade. Os conceitos, no entanto, são longínquos. De quando em quando, precisa-se negligenciar o presentismo, lembrando que a elaboração teórica é resultado de um longo processo reflexivo. Os conceitos se reelaboram constantemente. De Kant a Carus, passou-se das dúvidas propositivas entre razão e emoção na apreensão do mundo exterior, até o desenvolvimento da interação entre sentimento e ambiente.

A natureza não existe somente em exterioridade. Interage com o olhar inquisidor. A postura contempladora se responsabiliza pela indução de diversas sensações. Se os homens são diferentes, revelam, contudo, uma identidade comum na busca daquilo que possuem de divino. Perseguir a perfeição torna-se possível no reconhecimento do belo. E daí deriva a paisagem.

\section{Margareth Afeche Pimenta}

Universidade Federal de Santa Catarina, Curso de Arquitetura e Urbanismo, Programa de Pós-Graduação em Geografia. Florianópolis, SC/Brasil. afeche@arq.ufsc.br

\section{Notas}

(1) "Tuit li omne de ciel païs, trestuit apresdrent a venir; Et sancz Lethgiers lis predïat", extraído de La Vie de Saint Léger, escrito por volta de 980, publicado por J. Linskill (Paris, 1937). Disponível em: www.hs-augsburg.de/ harsch/gallica/Chronologie/10siecle/Leger/leg_text.html. Acesso em: 13 fev 2014.

(2) Benedei, monge que teria vivido na Corte de Henrique I, no início do século XII, é autor da vulgarização da Viagem do Santo Brendan, um poema edificante em octossílabas, traduzido por Ian Short (Guidot, 2015).

(3) A polêmica com Kant explicita-se em sua obra Kalligone (contre la critique du jugement de Kant), publicada em 1800.

(4) Preferiu-se, aqui, o texto em italiano, porque explicita os termos empregados em alemão. 


\section{Referências}

BRÉAL, M. e BAILLY, A. (1885). Dictionnaire étymologique latin. Paris, Hachette.

CARUS, C. G. e FRIEDRICH, C. D. (1983). De la peinture de paysage dans l'Allemagne romantique. Paris, Klincksieck.

CLARK, R. T. (1955). Herder: his life and thought. Oakland, Califórnia, University of California Press.

CNTRL (Centre National de Ressources Textuelles et Lexicales). Trésor de la Langue Française Informatisé (TLFI). Disponível em: http://www.cnrtl.fr/etymologie/. Acesso em: 11 jul 2015.

DÉCULTOT, E. (2006). Métaphysique ou physiologie du beau. La théorie des plaisirs de Johann Georg Sulzer (1751-1752). Revue germanique international, n. 4. Disponível em: http://rgi.revues. org/146. Acesso em: 11 out 2012.

(2015). "Lettres sur la peinture de paysage, livre de Carl Gustav Carus". In: Encyclopædia Universalis. Disponível em: http://www.universalis.fr/encyclopedie/lettres-sur-la-peinture-depaysage/. Acesso em: 20 jun.

FÉRAUD, J.-F. (1788). Dictionnaire critique de la langue française. Tome 3. Marseille, Jean Mossy.

FILLERON, J.-C. (2005). “ Paysage ”, pérennité du sens et diversité des pratiques. Actes Sémiotiques. Actes de Colloque, novembro de 2005. "Paysage et Valeurs: de la représentation à la simulation". Université de Limoges. Disponível em: http://epublications.unilim.fr/revues/as/1226. Acesso em: 10 set 2012 .

FR. Dictionnaire de l'Académie Française (1694, 1762, 1798, 1832-5, 1932-5, 1992). Paris, Académie Française. Disponível em: http://dictionnaires.atilf.fr/dictionnaires/ACADEMIE/. Acesso em: 22 nov 2014.

GUIDOT, B. (2015). Le Voyage de Saint Brendan par Benedeit: une aventure spirituelle? Universidade de Reunião. Disponível em: http://tice2.univ-reunion.fr/. Acesso em: 11 jul.

HERDER, J. G. (2009). Sul conoscere e il sentire dell'anima umana. Osservazioni e sogni 1. Revista Aisthesis - pratiche, linguaggi e saperi dell'estetico, anno II, n. 1, pp. 99-129.

(2013). Du connaître et du sentir de l'âme humaine. Paris, Editions Allia.

HERR, L. (1923). Avant-propos. Correspondance entre Schiller et Goethe (1794-1805). Paris, Librairie Plon. Disponível em: http://cdn.notesdumontroyal.com/document/503a.pdf. Acesso em: 22 jul 2015.

HILL, D. (2013). "Sturm und drang". In: MURRAY, C. J. Encyclopedia of the Romantic Era, 1760-1850. Routledge?.

HUMBOLDT, A. de (1850). Tableau de la Nature. Tome 1. Hoefer. Paris, Librairie de Firmin Didot Frères. Disponível em: htttp:// wwwgallica.bnf.fr. Acesso em: 27 jun 2015.

(1855a). Cosmos. Essai d'une description physique du monde. Tome 1. Paris, Gide et J. Baudry Editeurs. Disponível em: http// www.gallica.bnf.fr/. Acesso em: 20 jun 2015.

(1855b). Cosmos. Essai d'une description physique du monde. Tome 2. Paris, Gide et J. Baudry Editeurs. Disponível em: http//www.gallica.bnf.fr. Acesso em: 20 jun 2015. 
HUMBOLDT, A. de e BONPLAND, A. (1814). Voyage aux régions équinoxiales du Nouveau Continent, fait en 1799, 1800, 1801, 1802, 1803 et 1804. Tome 1. Paris, F. Schoell. Disponível em: http:// www.gallica.bnf.fr. Acesso em: 24 jun 2015.

KANT, E. (1846). Critique du jugement. Suivie des observations sur le sentiment du beau et du sublime. Tome 1. Paris, Librairie Philosophique de Ladrange.

KORINMAN, M. (2015). Schlegel August Wilhelm Von (1767-1845). In: Encyclopædia Universalis. Disponível em: http://www.universalis.fr/encyclopedie/august-wilhelm-von-schlegel/. Acesso em: 24 jun.

LEFEBVRE, H. (1974). La production de l'espace. Paris, Éditions Anthropos.

LITTRÉ, É. (1874). Dictionnaire de la langue française. Tome 3. Paris, Hachette.

MARTINELLI, R. (2010). Entre toucher et sentiment. Herder et le “Gefühl. Esercizi Filosofici, n. 5, pp. 1-7.

MONDZAIN-BAUDINET, M.-J. (2015). Sulzer Johann Georg (1720-1779). Encyclopædia Universalis. Disponível em: http://www.universalis.fr/encyclopedie/johann-georg-sulzer/. Acesso em: 15 jul.

MORIN, E. (2003). A cabeça bem-feita. Rio de Janeiro, Bertrand Brasil.

NICOT, J. (1606). Trésor de la langue françoise en tant ancienne que moderne. Paris, David Douceur.

OXFORD RESEARCH ENCYCLOPEDIAS (2015). Oxford University Press. Disponível em: http://www. oxforddictionaries.com/. Acesso em: $15 \mathrm{dez}$.

PÉNISSON, P. (1996). Kant et Herder: le recul d'effroi de la raison. Revue germanique internationale. Disponível em: http://rgi.revues.org/579 a partir de 9 setembro 2011. Acesso em: 11 out 2012.

PIERLOT, P. (2015). Emergence du concept de Stimmung dans le dernier tiers du XVIII ${ }^{e}$ siècle. Disponível em: http://docteurpascalpierlot.fr/wp/chroniques/quest-ce-que-la-stimmung/stimmungemergence-du-concept/. Acesso em: 19 jun.

RICHELET, P. (1728). Dictionnaire de la langue Françoise Ancienne et Moderne. Tome Troisième (P-Z). Lyon, Les frères Duplain.

RICHIR, M. (2015). “Affectivité”. In: Encyclopædia Universalis. Disponível em: http://www.universalis. fr/encyclopedie/affectivite/. Acesso em: 19 jul.

SANTOS, M. (1982). Pensando o espaço do homem. São Paulo, Hucitec.

(1985). Espaço e método. São Paulo, Nobel.

SCHILLER, F. e GOETHE, J. W. von (1923). Correspondance entre Schiller et Goethe. 1794-1805. Tomo 1. Collection d'Auteurs Étrangers, publicada sob a direção de Charles du Bos. Paris, Librairie Plon.

Texto recebido em 14/jan/2016

Texto aprovado em 31/mar/2016 
